\title{
HAS THE PSYCHOLOGICAL LABORATORY PROVED HELPFUL?
}

HIS is a question stated in such a way that many
people will find in its very statement a negative reply. But my intention here and now is to put a question without giving the answer, to state a problem without solving it. It is something indeed to state the question. Were I to give an answer it would demand more time than I would be justified in consuming. I will not give the external history of the laboratories; this would avail us less than one might think. My task is more modest or more pretentious as you prefer; I confine myself to mental impressions, which, nevertheless, can bring us nearer to the truth than history. How many times an institution conceived and established in a certain spirit ends by working in a different spirit to serve still another spirit.

A psychological laboratory!-I do not know what there is in the shop, but it must be admitted that it could not have a droller sign. You may say I am jesting but there is no other way to interpret the expression than somewhat after this fashion: Here ideas are manufactured, volition is distilled, sentiment is created. So it seems that even the intent and the conception of a psychological laboratory must be the result of a misapprehension and at the service of this misapprehension; it seems that philosophy has noth-

1 Address delivered on September 4, I908, before the Third International Congress of Philosophy at Heidelberg; translated from the French manuscript of Professor Billia by Lydia G. Robinson. 
ing to do but to refrain from taking interest in it, or perhaps to enter just once in order to administer charitable advice and to give the savants in charge of the laboratories a little instruction in modesty and prudence by making them see how vain and deceptive is the pretense at studying and knowing the facts of consciousness outside of consciousness, and how greatly one is deceived by the most pitiful illusion when he imagines that what he measures, what he pulls and puishes, what he weighs, and what he analyzes by the aid of material things is really consciousness, thought, sensation.

But in this task of removing a misconception, we soon meet with a difficulty which proves a hindrance; or, rather, restrains us for the time being and makes us consider the matter once more. We are not overawed by the insolence of those who appear to work for the purpose of reducing the facts of consciousness to the measurement of material facts; on the contrary what has detained us is the good faith, the serious spirit and the useful contributions of others who are true experimenters. With what right are we to teach modesty to modest men, logic and the limits of experimental research to those who pursue the study of its logic and are well aware of its limits? When we step into the laboratories of the Claparedes, of the Flournoys, of the De Sarlos, of the Kiesows (I can not undertake to make the list complete) we find ourselves face to face with men who tell us without any reservation that they are in search of facts only, that they do not work in behalf of a system or a party but for the single purpose of contributing to the knowledge of mental facts. These are the men who do not wait for our reservations to assure us that they have never pretended to tell us what sensation is or what thought is, nor whence they originate, but only to determine some conditions of the nervous system, or the organism, and even of the environment in which the 
facts of consciousness are produced in such and such a way, and even when they are produced or when not. This has impressed us; it has disarmed us; it has instructed us.

Further, truth has nothing to fear from truths. We have readily understood that this serious study of the external and physiological conditions of the facts of the soul would have brought us at the same time to a better recognition of these facts and to the clearer and clearer distinction between these facts and their permanent conscious and individual principle on one side, and on the other of the somatic conditions in which they manifest themselves.

Finally, there is no other point in question than to be able some day to give an exact solution to this correspondence of each different instant which obtains in the consciousness of every person. Formerly I tried to reduce this correspondence mainly to a limitation of the power of reflection, ${ }^{2}$ which becomes manifest in the consciousness even of philosophers at certain hours of the day when in a state of fatigue, exhaustion or intoxication, and which indeed may be the condition of the whole life of certain unfortunates whom we call fools, simple minded, and idiots. If this solution could be reached how many problems would be solved! There would then be some hope of carrying out the old well-known and very audacious assertion of Descartes that medicine would one day be able to govern the mind and the character; that is to say, to deliver humanity from evil and disorder. Education would no longer have to struggle continually against difficulties and recurring deceptions, because it would know in advance what might be expected of each individual under definite conditions.

This is a matter of which we have had some idea for a long time. We might even find precursors of psycho-phys-

'Lezioni di Filosofia della morale, VII. Rome, Torino, 1897. Ernest Naville e il libero arbitrio. Rome, Torino, Ig00. 
ics in the greatest metaphysicians of earlier days. An investigation which I myself have made with the intention of proving that the great metaphysicians were also great masters of observation, has led me to discover an advanced psycho-physics not only in Rosmini who is too modern to prove my point, but in Malebranche and even in Plato. ${ }^{3}$ That which was then still lacking and could not be expected until the science of to-day and of the future, was measurement and exact determination. The nearer we approach to this measurement and exact determination, the more we see that it by no means supplants the idea of the mind and of its action upon itself, not even pretending to explain its production, its origin and nature; but only to establish limits and conditions, in such a way that even if the laboratory was established for materialistic purposes its triumphs and its most serious results have been in the service of spiritualism. As my friend M. Adrien Naville has said: "It will always be understood more clearly in proportion as the physiology of the brain progresses. Anthropological monism can only live in the twilight. When physiologists shall have succeeded in expressing in definite mechanical formulas the movements of the cerebral cells which are analogous to facts of consciousness, no one can insist that these facts of consciousness are the same thing as a movement."'

The evident conclusion from all these observations and all these considerations will therefore be that psychological laboratories are the more useful and conspicuous an aid to the study of the mind according as the expectations of the scholars who looked forward to them are more modest, and the results more precise, definite, determined, positive.

But there is a train of ideas which carries us along in

- Delle dottrine psicofisiche di Platone, Modena, 1898; Esti. d. Atti d. Accademia. Delle dottrine psicofisiche di Nicolò Malebranche, Berlin, 1900. L'esiglio di $S$. Agostino, Turin, 1898.

'Revue Scientifique, Mar. 5, 1887, p. 316. 
spite of ourselves. We have seen that the psychological laboratory has carried the materialist and the positivist in the direction of spiritualism. But whither is the spiritualist led who, disarmed by the modest and earnest bearing of his ancient adversary, enters into the laboratory, shuts himself up, and abandons himself to the confident expectation of finding there a more exact confirmation of all the truths of his consciousness and one more suitable for persuading others?

I. In proportion as he acquires a more precise, more exact, more definite knowledge of physiological, and even of physical and chemical conditions, in which and under which such a fact of sensation, of thought, and of will is produced, he runs the risk of losing the clear vision of what this fact truly is; very much as those literary critics who are better informed about the exact day and hour of Dante's birth and the exact spot in Florence where his house stood and about the gate of the town from which he departed to take his flight in exile, are not always the ones who best penetrate into the spirit of the loftiest of poets. By seeing that a phenomenon occurs under such circumstances, one is led to believe that it has not occurred and does not now occur except under such circumstances; and with this we have now come back to the prodigious misapprehension of a fact of consciousness studied outside of consciousness. In other words, in spite of the best intentions to the contrary, psychology itself is destroyed by the psychological laboratory.

II. Again, the experiments in the laboratory give us such a habit of considering and measuring the limitations of our power of feeling, of understanding, and of willing, that they lead us to forget another side of our psychical life which is no less a true side, namely liberty, and the power of passing beyond those very limits, and of extending our faculty of feeling, understanding and of willing 
still farther beyond. Certainly to find an exact determination of the physiological and physical limits of our intellectual and volitional operations appears to be a great triumph, but in the first place who said that this determination would be the same for all? or that it always results in the simple combination, that $a$ being given as the sumtotal of physiological conditions we will have $b$ for the sumtotal of psychical conditions and that each change which takes place in $a$ leads necessarily to the same change in $b$ ? This indeed would be a most comfortable and alluring theory, but here is where consciousness will have to do with facts which throw a great suspicion of doubt upon this formulation. Psycho-physical correspondence ${ }^{5}$ is not at all constant. I am not a pragmatist not a Bergsonian. I do not say that it defies all rule, all possible determination, I simply say, and I insist upon it, that it is not confined within the limits of the determination furnished by the laboratories or through the laboratory method. For instance, it is easy to admit that during the day in the ordinary life of a healthy person with a good constitution, and still more during the day and in the ordinary life of a person somewhat delicate and ailing, there is a physiological limit beyond which he loses the power of reflecting which should operate in two processes becoming more and more painful and finally unbearable; viz., the effort to pay attention to a long and complicated series of ideas, of symbols, and of images, or of circumstances which compel a decision to be made; and the effort to fix one's mind for a long time upon the motives which persuade us to endure to the end something requiring great patience. For instance, you all agree in admitting that you could not endure the tiresomeness of my discourse for three hours, and, for my part, I could not endure certain noises for a few consecutive minutes

shose who do me the honor to grasp my thought will have to content themselves with the word correspondence. Identity would indicate too much and parallelism too little. 
without being greatly disturbed. They say, or at least we are constantly besought to have the decency to believe, that the learned physiologists have determined by exact measurement the intoxication of nerve centers, the exhaustion of nervous and muscular force, the breaking down of tissues, especially in the brain, which corresponds to the mental relaxation as its only cause.

But right at this point, if many facts seem to justify these conclusions, other facts, less numerous to be sure but well established and authenticated, give the lie to the pretensions of those who would measure exhaustion if they try to give the results of their experiments as an absolute and universal law. If a tyrant were to make my lecture last four hours the rest of you though reduced to extreme exhaustion would still be able to give your attention to a soothing melody which some solacing spirit might cause to resound and even to a homelier fanfare from the street. However, it is a fact of almost elementary physiology that because of the multiplicity of vibrations the nervous fatigue of a man who listens to the best of concerts is far greater and far more exhausting than that of him who listens to the dullest of lectures.

Soldiers who faint from thirst and fatigue and are no longer conscious of their surroundings will throw themselves once more into the assault if they are made to believe that victory is sure or that their safety rests on the condition of one supreme effort. Those who, like myself for instance, have a very delicate nervous system often experience moments of such exhaustion that they require absolute and immediate relaxation and repose. There must not be the slightest delay for this recuperation, no noise, nor any effort of attention. Now if under these conditions we come home and find that some member of the family has suddenly been taken ill, that a child is in danger, that the daily paper has given a false report prejudicial to our 
scientific or political reputation or to our party, and that its refutation cannot be postponed later than the edition of the following morning, we are at once ourselves again, we summon our forces, our attention, and we postpone our fatigue, dismissing all thought of supper and bedtime.

It is true that we have reserve force. but this only succeeds in deferring the difficulty. It is according to our discretion that we draw upon these reserves, therefore the limit is not absolute, - or if there is an absolute limit it is not the physiological limit; or if it is always a physiological limit it is not the one which the laboratories determine or are able to determine.

Please consider once more that this extension and widening of limits which takes place suddenly in the presence of a motive may in certain individuals indeed become a constant exercise, the limits to be extended day by day, and powers of feeling, thinking, and willing to be indefinitely increased. The laboratories teach us these limits. Consciousness here confronts us with a great mystery; where are the limits? As soon as the limit of one instant can be removed to the instant after and so on, is there still another limit in this power of extending the limit? I state the question but I do not expect it to be answered. I have only to say that this is the great question of psychology; I have only to say that the laboratory which forgets it, in so doing destroys psychology.

To be sure, to give us an idea of limits which is perhaps instructive and wholesome, may render us more discerning towards ourselves and towards others, may give us the wisdom to avoid claiming the impossible. But the habit of always taking physiological limits into consideration may also stifle the consciousness of our inner powers, the consciousness of the power of the mind acting with an ideal in view. More discerning alas! But it has also given us a cowardly habit of considering certain disorders such 
as debauchery, drunkenness, slavery, war, and capital punishment, as if they were determined by external and organic conditions, and to forget the agency of liberty and its power in degenerating as well as in upbuilding,-agency and power which are no less positive facts than all the physiological determinations, and moreover are themselves the determining factors.

III. Finally, the psychological laboratory leads us to treat mental facts as external objects of experimental research and curiosity. But mental facts are not that. The mind which we observe is nothing else than we ourselves who live and ought to exist in a certain manner. The question is not to see how some one or some thing operates. The important thing is that we ourselves should always be and do well,-always better. There are experiments which should not be performed because they injure us, deteriorate us, remove us farther from perfection. Only those experiments should be performed which in themselves are a step in our development. Not all curiosity should be satisfied because its satisfaction is at our expense, because it is on ourselves that the experiment is made.

A bigoted man of science may challenge me with the scandalized question: Would you found education upon ignorance? Not at all; it would be offensive to say and absurd to think. But it is well to have the courage to state clearly that some ignorance is an indispensable element of education. Why? Precisely because at bottom human education is in no way possible unless it is founded on science, which is at the same time both the means and the end of education. Now some ignorance is the indispensable condition of all knowledge. I may know all the gossip of the town, yet I will be very ignorant not in spite of this, but on account of it. You are scholars not only because of the attention you have given, but also because of that 
denied. Whoever wishes to acquire a practical acquaintance with the sights and especially the sensations, of cruelty and debauchery, must condemn himself to ignorance of decent and charitable feelings, or at least of the noblest sentiments of mankind; and vice versa, he who would acquire a true, faithful and complete knowledge of these must needs renounce forever not only the practice of the wrong things but knowledge of them as well. Still considering the lack of a system and the brevity of life and other hindrances to vast knowledge, it is by no means impossible to form a truly cultivated mind without sacrificing a great deal of detailed and encumbering erudition and without yielding either to the many particulars of that form of presumptuous ignorance which is called specialism, or to a large part of the medley of the other form which may be called encyclopedic. We owe the greatest portion of our knowledge to books that we have read; but much also to our good fortune in having escaped reading many others.

My position with regard to these observations is that of a $\phi \iota \lambda о \mu a \theta \eta^{\prime}$ ' but not a partisan; consequently I like to consider the matter in all its aspects. I have often thought of one thing which seems to contradict my conclusions. A large part of the studies of physicians accustom the young men to a familiarity with sights which on account of their nature and circumstances are by no means apt to cultivate respect and delicacy of feeling. Nevertheless being acquainted with many physicians I have no right nor inclination to participate in the unfavorable opinion of them professed by Jean Jacques Rousseau-although otherwise he was so compassionate in his writings; for I have observed it to be an undeniable fact in the case of many physicians and surgeons that they have preserved and cultivated as delicate, tender and sympathetic a heart as the gentlest and mildest maiden. I have observed this in phy- 
sicians and surgeons who were noted for having held the greatest number of autopsies. I account for it by the mastery over impressions and feelings held by a mind dominated by the idea of duty; viz., a strong well-formed and well-balanced character is able to overcome his repugnance to the hideous and shocking, precisely for the purpose of respect and goodness, braving the repugnance from a higher motive when there is need, sacrificing self when demanded by justice and decency. The same principle impels the good physician to insert the knife into the flesh and inspires him to endure the most exacting fatigue, endeavoring to prevent any suffering to the patient rather than avoiding an indecent or indelicate sight.

But the conclusion I draw is by no means negative or to throw doubt on the preceding considerations, or to limit inquiry. On the contrary, this is my conclusion: Since medicine alone is not able to make or mar the man, but its task is most critical, and the physician's aim most delicate and sublime (viz: not the recovery of an organ, but the health of the man), medicine ought finally to be understood not at all as a mercenary trade, but as a priestly office, a mission of devotion the function of which is charity; and we should require of the physician a proportionately moral superiority. Whenever found it is reasonable to attribute this superiority to individual character; and to doubt whether the discipline and curriculum of our universities makes any provision for it.

Psychology is not the same kind of a science as pure chemistry or pure mathematics whose object is something else than the subject which studies and observes. Psychology is the science of ourselves and our actions, and our actions are in process while being observed. It is the science of the self and nothing can be observed with regard to the self unless it be the self or a part of the self.

I do not think in the least that I am the first to make 
a discovery in pointing out this singular condition of psychology which distinguishes it from all other sciences. $\mathrm{My}$ purpose is only to call the attention of the studious to a fact which should not be forgotten and to deduce from it a conclusion which may perhaps be new, and in any case stands out in bold relicf. No science changes its object: the mathematician makes no change in the nature and relation of numbers; physicists and chemists do not create the phenomena which they report. If accidentally the environment disturbs the experiment and unexpected compositions are formed, the mistake must be at once corrected and the disturbing factor removed. Or perhaps a new property is discovered or it becomes clear that it is impossible to make the experiment; in any case the novelty of the phenomenon is not attributed to the experimenter simply because he observes it and makes a note of it.

In psychology quite the contrary is true. The observation that is made of the facts of the soul does not leave the facts as they were before. If I perceive that I am ignorant, I am no longer as ignorant as I was. If I perceive that I am wicked, I would naturally begin to overcome a part of my wickedness. He who perceives that he is in love is no longer in love in the same inanner or the same degree as he was. Perhaps he becomes more so, perhaps less, but never the same. He who nurses his passion each day and each hour and examines it with a critical eye, either causes it to grow to the loftiests heights or else effaces it by his analysis. Never will it remain the same; never would he be able to say to himself, "Up to this point it was spontaneous; afterwards voluntary, cultivated." The spontaneous to which consciousness bears witness ceases to be spontaneous.

It is for some purpose that we are woven in the fabric of self, quite simple though it seems, and even with respect to matters which we deem of minor importance. If I per- 
ceive that I am sick, perhaps in my stomach, I become at once a little more or a little less sick than before and the same thing is true if I perceive, if I state, if I declare that $I$ am recovered, if $I$ wish to recover. Nothing is more real than the diseases which are called imaginary. If this is true beyond doubt in the action of the first acts of consciousness, how much more true would it be in a series of acts of consciousness purposely continued, of attention, and of reflection, such as form the subject of psychology? Rosmini who pointed out this fact long before and much more clearly than Wundt, recognizes here one of the difficulties of introspective observations, and a less fortunate condition than that of physical observation. ${ }^{8}$ But one might as well conclude that psychology, although absolutely lacking in scientific precision as it is, possesses after all a greater value than all science. Whether harmful or beneficent, psychological study would never be useless or indifferent. It is quite impossible that observation, study, and psychological science, or the concern for psychology, would not modify profoundly and to a great extent the soul, the mind, the affections, conduct, and finally society itself even if psychologists would not assume, even if they would refuse, the character of apostles. This then is another source of the considerations which lead us to conclude that psychology is not a curiosity such as laboratories make it or may make it. Nor is it only, as puny pedagogues teach, preliminary to the science of education; it is education itself.

In the self one should not admit the good and the bad, the higher and lower, the refined and the common, as two varieties equally interesting and worthy of study, but only the good, the higher and the fine should be admitted and cultivated. The evil, the lower, and the coarse ought not to exist, and if they do they should be exterminated. Psy-

- Logica, p. 952. 
chology is not a curiosity; there is but one aim of science, perfection. The laboratory forgets this fact too often. I say it forgets, and do not refer to some criminal experiments which are not mere forgetting or due to ardor and which I would recommend not to science but to the regular police department. But even in simple negligence, even in that eagerness which has made of psychology a research into conditions and effects without consideration of endeavor and liberty, one may say that in spite of all its good intentions, the psychological laboratory destroys psychology and also ethics.

Should then the laboratory be suppressed and its doors closed? Not at all. I have said that I would state questions and not that I would draw conclusions. I would only make a proposition. It is not necessary to suppress anything or to close anything. It is necessary to uplift. Let us raise the standard of the laboratory. First of all it must become truthful. It can do so by dispensing with a name which is a contradiction. Psychology does not operate in a iaboratory. The true laboratory of psychology is nothing but consciousness.

Here I shall insert a parenthesis, even if it destroys to some extent the harmony of my discussion, in order to answer in advance an important objection which may be made to my position. Apparently I have exposed myself to being addressed thus: In speaking of psychological laboratories you have limited your attention to the psychophysiological laboratories which measure the effects and the organic conditions of mental acts; you have ignored or neglected those other laboratories where measurements are not taken but records are made of observed facts, of statistics; as for instance how many of the one hundred individuals who daily enter the same door would be able to answer accurately questions about the number, size or arrangement of the windows of the building? Out of one 
hundred pupils in a school how many will we find who are able to pay strict attention for a quarter of an hour, etc., etc.?

I have considered the point well. Measurement and the pretense of psycho-physical equivalence served the purpose of my argument more simply and clearly, but my aim was directed against every attempt to study the facts of consciousness outside of consciousness. There are three points of criticism which even the psychological laboratories that renounce physical measurements in favor of statistics, do not entirely escape:

I. Psycho-statistical researches can have no accuracy unless they take into account the organic conditions of race, health, development, and nutrition. That is to say, out of 100 there are perhaps thirty who pay attention and seventy of whom not one would have any opinion except with regard to how long it was since he had a meal, whether he slept well the night before, whether he is anaemic, who are his parents, where he comes from, how his stomach, heart and lungs perform their functions. Hence psycho-statistical researches have no value unless they are founded on psycho-physical investigation and measurements, and if they depend on these they are subject to the same criticism as the latter.

2. They also fall under the criticism of making a curiosity of psychology while forgetting that its purpose is education.

3. Statistical psychology having for its aim the establishment of a certain determinism also leads us to exaggerate its limits, but perhaps a little less than physiological psychology. Perhaps it can also give us some idea of those who exceed the ordinary limits and stimulate us by such examples to exceed them ourselves. But so much the better. I do not wish to be destructive.

However, the fundamental misapprehension remains, 
-the illusion of studying outside of consciousness a fact which takes place only within consciousness and which outside of consciousness is not even conceivable.

Therefore let us retain and preserve experimental investigations on the nervous systcm, and if we wish to keep the name of psychological researches let us expand them. Instead of confining ourselves to studying limits, conditions leading to psychical disorders, or even to provoke them which would be criminal,--let us study in consciousness the power of the mind, endeavoring to see to what point in ourselves we can cultivate self-denial, the power of attention, growth, development of faculties, and of the hidden varieties of feeling, understanding and willing, the power of abstraction, devotion, affection. Let us care for the insane and the sick, but let us cultivate especially heroes, saints, and superior beings.

Lorenzo Michelangelo Billia.

Turin, Italy. 